Article

\title{
An eLORETA Longitudinal Analysis of Resting State EEG Rhythms in Alzheimer's Disease
}

\author{
Serena Dattola *(D) and Fabio La Foresta \\ DICEAM Department, Mediterranea University of Reggio Calabria, Via Graziella Feo di Vito, \\ 89060 Reggio Calabria, Italy; fabio.laforesta@unirc.it \\ * Correspondence: serena.dattola@unirc.it
}

Received: 7 July 2020 ; Accepted: 13 August 2020 ; Published: 15 August 2020

\begin{abstract}
Alzheimer's disease (AD) is a degenerative brain disorder which is the most common cause of dementia. As there is no cure for AD, an early diagnosis is essential to slow down the progression of the disease with a proper pharmacological treatment. Electroencephalography (EEG) represents a valid tool for studying AD. EEG signals of AD patients are characterized by a "slowing", meaning the power increases in low frequencies (delta and theta) and decreases in higher frequency (alpha and beta), compared to normal elderly. The purpose of our study is the computation of the power current density in eight patients, who were diagnosed with MCI at time T0 and mild AD at time T1 (four months later), starting from the brain active source reconstruction. The novelty is that we employed the eLORETA algorithm, unlike the previous studies which used the old version of the algorithm named LORETA. It is also the first longitudinal study which considers such a short time period to explore the evolution of the disease. Five patients out of eight showed an increasing power in delta and theta bands. Seven patients exhibited a lower activation in alpha 1 and beta 2 bands. Finally, six patients revealed a decreased power in alpha 2 and beta 1 bands. These findings are consistent with those reported in literature. On the other hand, the discrepancy of some outcome could be related to a not yet severe stage of the disease. In our opinion, this study could represent a good starting point for more detailed future investigation.
\end{abstract}

Keywords: Alzheimer's disease; mild cognitive impairment; EEG; eLORETA

\section{Introduction}

Alzheimer's disease (AD) is a brain disorder causing a progressive decline in cognitive functions. The diagnosis of the disease is based, initially, on the evaluation of neuropsychological and behavioral symptoms related to disorders of memory, language, and visual-spatial perception [1].

There are four stages which characterize the evolution of the disease: In the first stage, called Mild Cognitive Impairment (MCI), the subject shows short-term memory loss and difficulty in remembering even words of daily use. These symptoms, however, do not substantially affect everyday life. This condition is not always irreversible because not all MCI subjects convert to AD-it happens for $50-60 \%$ of them. During the next two stages (Mild and Moderate AD) the patient shows difficulty in recognizing relatives and friends, and suffers from spatial and temporal disorientation. Moreover, the first behavioral changes appear, such as anxiety, insomnia, and personality changes. During the last stage-Severe AD—-the patient no longer recognizes anyone; does not understand words; and has difficulty in dressing, eating, and swallowing. The subject is completely dependent on caregivers. Death occurs because of the further worsening of these symptoms [2-4]. To date, there is no cure for Alzheimer's disease, but several medications are used for delaying the onset of the symptoms and improving the patient's quality of life. Therefore, early diagnosis of AD is very important because the 
medications are effective only if taken during the first stage. However, the diagnosis is hard because the first symptoms are often mistaken for normal aging [5].

During the last decades, neuroimaging methods—-such as magnetic resonance imaging (MRI) and positron emission tomography (PET) - have played an even more important role in diagnosing AD [6-8]. Nevertheless, most of them are expensive and rather invasive, thus the need of a tool which overcomes these drawbacks. Electroencephalography (EEG) represents a valid technique to detect any pathological alterations in the brain $[9,10]$. EEG is a low cost and noninvasive instrument, which records the brain electrical activity by means of electrodes distributed on the scalp. In particular, the signal is produced by the sum of postsynaptic potentials generated simultaneously by population of cortical pyramidal neurons. The EEG signal derives from the contribution of all active sources because of the conductivity of the scalp, the skull and the brain. Therefore, the choice of a realistic head model is essential for a correct EEG analysis [11]. EEG is characterized by an excellent temporal resolution, on the order of milliseconds; conversely, the spatial resolution is poor.

EEG has been successfully employed for investigating AD [12-16]. Several studies have proven that the EEG frequency bands are affected by AD in a specific way. In particular, the spectral analysis shows a "slowing" of EEG signals in MCI and AD patients: the power increases in low frequencies (delta and theta) and decreases in higher frequency (alpha and beta), compared to normal elderly (Nold) [17-22]. Moreover, the EEG signals of AD patients are characterized by less complexity and a reduction of synchronization between different areas of the brain $[5,23,24]$.

The current flows generated by neurons can be modeled with dipoles. The localization of cortical sources which produce the EEG rhythms requires the solution of the so-called inverse problem. It is an ill-posed problem which has infinite possible solutions, because the number of the known parameters (electrodes) is lower than the number of the unknown parameters (current density of the sources). Therefore, the solutions are regularized using mathematical and neuroanatomical constraints, in order to choose the most likely solution. One of the most employed algorithm for solving the EEG inverse problem is Low-Resolution Electromagnetic Tomography (LORETA) [25]. It belongs to the high temporal resolution neuroimaging method and provides a 3D reconstruction of the cortical electrical activity. Over the years, LORETA has been widely employed for studying the spectral power density of EEG signals in AD. Babiloni carried out several studies about this topic. In [26], the results showed that the power in alpha 1 declined in AD in the central, parietal, temporal, and limbic lobes as compared to Nold. Alpha 1 power in the occipital lobe was lower when the disease was at a more severe stage. There was also an "anteriorization" of alpha 1 rhythm, as the power decreased much more in the parieto-occipital area than in the frontal one. As for the theta band, there was no significant difference between mild AD and Nold. This study was extended in [27], as it included also MCI. The findings revealed that, in comparison to Nold and mild AD groups, MCI group had intermediate power in delta (occipital area) and alpha 1 (parietal, occipital, temporal, and limbic areas) bands and greater power in alpha 2 (occipital area) band. In [28], the correlation between the disease and the hippocampal volume was explored. For the alpha 1 band, the activity was maximum in $\mathrm{MCI}$ with greater hippocampal volume, intermediate in MCI with smaller hippocampal volume, and minimum in AD. The study conducted in [29] showed that for MCI and AD subjects, posterior delta and alpha EEG rhythms do not decline when white matter vascular lesion increased. In [30], it was found a positive correlation between the gray matter volume and the alpha 1 power and a negative correlation with delta power in $\mathrm{MCI}$ and AD. Canuet and colleagues [31] reported a significant reduction of alpha 1 activity in the parieto-occipital regions for $\mathrm{AD}$ as compared to healthy subjects. In [32], the authors found a positive correlation between the severity of the disease and delta power and a negative correlation with alpha 1 power. The study in [33] showed a greater power in delta band in large areas, including the frontal lobe, in AD in comparison to controls. All the above-mentioned papers refer to cross-sectional studies. In the literature, there are only three longitudinal studies that applied LORETA. In [34], the EEG power of a group of MCI patients was evaluated during a follow-up of approximately 14 months. Twenty-four subjects converted to $\mathrm{AD}$, whereas 45 subjects remained stable. The results showed that 
the EEG power for delta (temporal area), theta (temporal, parietal, and occipital areas) and alpha 1 (central, temporal, parietal, occipital, and limbic areas) bands was significantly higher in MCI who converted to $\mathrm{AD}$, as compared to $\mathrm{MCI}$ stable. The remaining two works were carried out by Babiloni and colleagues. In [35], a group of MCI patients were examined about 1 year after the first EEG recording. The subjects were divided into three groups, according to their MMSE score variation, as "stable", "decreased", and "increased". The only significant difference was detected for the alpha 1 band: the temporal, parietal, and occipital power density was greater in the stable group than in the decreased and increased groups, suggesting that preserved resting cortical activity at alpha band is related to a long-term stable cognitive function in MCI subjects. Resting state EEG of a mild AD group was investigated in [36]. The second recordings were carried out after 1 year. The alpha rhythm was characterized by a widespread power decrease as well as the temporal, parietal and occipital beta 1 band. It was also shown an increased power of delta sources in all brain areas except for the central region.

Motivated by the encouraging results of the above-mentioned works, at least at group level, we propose a preliminary study to evaluate whether resting state EEG sources can be markers for the prediction of the disease progression, from $\mathrm{MCI}$ to $\mathrm{AD}$, in a single subject. In particular, the purpose of our work is to explore the power current density in eight patients, who were diagnosed with $\mathrm{MCI}$ at time $\mathrm{T} 0$ and mild $\mathrm{AD}$ at time $\mathrm{T} 1$ (four months later). Starting from the brain active source reconstruction, the eLORETA algorithm was used for the computation of the power spectral density for each EEG rhythm and the results were grouped according to the brain lobes. The use of the eLORETA algorithm represents a novelty as compared to the above-mentioned studies, which employ the old version named LORETA. It is also the first longitudinal study that considers such a short time period to examine the evolution of the disease. Most results are consistent with those reported in literature. On the other hand, in our opinion the discrepancy of some outcome could be related to a still mild stage of the disease at time $\mathrm{T} 1$.

\section{Materials and Methods}

\subsection{Subjects}

Eight amnestic MCI patients (four males and four females) were enrolled by a team of experts at the IRCCS Centro Neurolesi Bonino-Pulejo of Messina (Italy). The subjects underwent a series of examination at time $\mathrm{T} 0$ and at time $\mathrm{T} 1$ (four months later). The doctors agreed that patients converted from MCI (at T0) to AD (at T1) on the basis of the Montreal Cognitive Assessment (MoCA) scores. The study excluded the subjects suffering from epilepsy, neurological or psychiatric diseases related to cognitive impairment, traumatic brain injuries, systemic diseases. Subjects who took psychoactive drugs were also excluded. The study followed a clinical protocol approved by the the local Ethics Committee (Prot. E29/16). The patients or their caregivers were notified of the procedure and signed an informed consent form. The demographic data of the subjects are reported in Table 1.

Table 1. Demographic data of the recruited subjects.

\begin{tabular}{ccc}
\hline Patient ID & Gender & Age \\
\hline Pt 03 & M & 68 \\
Pt 32 & M & 78 \\
Pt 41 & M & 78 \\
Pt 51 & F & 72 \\
Pt 71 & F & 79 \\
Pt 164 & M & 76 \\
Pt 180 & F & 78 \\
Pt 184 & F & 69 \\
\hline
\end{tabular}




\subsection{EEG Data}

The EEG signals were acquired in resting state with eyes closed but the subjects were awake. The data were recorded using a Brain-Quick System (Micromed) from nineteen channels, according to the international 10-20 system: Fp1, Fp2, F3, F4, C3, C4, P3, P4, O1, O2, F7, F8, T3, T4, T5, T6, $\mathrm{Fz}, \mathrm{Cz}$, and $\mathrm{Pz}$, with linked earlobe (A1-A2) reference. The artifactual segments were detected and marked by the doctors during the EEG acquisition. Those segments were not considered for the analysis. The sampling rate was $256 \mathrm{~Hz}$. It was applied a notch filter at $50 \mathrm{~Hz}$. Data were transformed to a common average reference montage and divided into artifact-free non-overlapping epochs of 256 samples (1s).

\subsection{LORETA}

LORETA was the first linear distributed method for solving the EEG inverse problem which provided a valid solution from the neurophysiological point of view [25]. LORETA, in fact, solved the matter of the large source localization error of the minimum norm method, which misplaced deep source onto the outermost cortex [37]. LORETA employs a three-shell spherical head model (MNI305) registered to the Talairach human brain atlas [38,39]. The head model is made up of the scalp, skull, and brain compartment. The brain compartment, limited to the gray matter and hippocampus, is discretized in 2394 voxels at $7 \mathrm{~mm}$ spatial resolution. Each source is placed on a voxel and is characterized by a current density vector with unknown components. Therefore, the potential recorded on the scalp derives from the electrical activity at each point. LORETA seeks the smoothest of all possible infinite solutions by means of a discrete spatial Laplacian operator. Therefore, the LORETA images represent the electrical activity at each voxel as power of the computed current density. Because of the smoothing, the location of the maximal activity is maintained but the images are "blurred". The average localization error is one voxel.

The expression of the general inverse problem is [40]

$$
\min _{J} F_{W}
$$

with

$$
F_{W}=\|\mathbf{\Phi}-\mathbf{K} \mathbf{J}\|^{2}+\alpha \mathbf{J}^{T} \mathbf{W} \mathbf{J}
$$

where $\boldsymbol{\Phi} \in R^{N_{E} x 1}$ is the vector of the electric potential differences measured at $N_{E}$ electrodes with respect to a single common reference electrode; $\mathbf{K} \in R^{N_{E} x\left(3 N_{V}\right)}$ is the lead field matrix corresponding to $N_{v}$ voxels, $\mathbf{J} \in R^{\left(3 N_{V}\right) x 1}$ is the current density, and $\alpha>0$ is the Tikhonov regularization parameter [41].

The solution is

$$
\hat{\mathrm{J}}_{\mathrm{W}}=\mathbf{T}_{\mathrm{W}} \boldsymbol{\Phi}
$$

here $\mathbf{T}_{\mathbf{W}}$ is the pseudoinverse, given by

$$
\mathbf{T}_{W}=\mathbf{W}^{-1} \mathbf{K}^{T}\left(\mathbf{K} \mathbf{W}^{-1} \mathbf{K}^{T}+\alpha \mathbf{H}\right)^{+}
$$

The matrix $\mathbf{H}$ is the average reference operator. For LORETA, the matrix $\mathbf{W}$ represents the squared spatial discrete Laplacian operator.

After a few years, the sLORETA algorithm was introduced [42]. Unlike LORETA, the brain volume is made up of 6239 voxels at $5 \mathrm{~mm}$ spatial resolution. The electric potential lead field used for the inverse solution is computed with the boundary element method applied to the MNI152 template [43,44]. Moreover, sLORETA abandons the use of the laplacian operator and is based on the standardization of the current density. Differently from the Dale method [45], which takes into account only the variation due to measurement noise, in sLORETA the estimated current density considers 
the variation of the actual sources and, if any, the variation due to noisy measurements. The electric potential variance is given by

$$
\mathbf{S}_{\boldsymbol{\Phi}}=\mathbf{K} \mathbf{S}_{\mathbf{J}} \mathbf{K}^{T}+\mathbf{S}_{\boldsymbol{\Phi}}{ }^{\text {Noise }}
$$

where $\mathbf{S}_{\boldsymbol{\Phi}}{ }^{\text {Noise }}$ is the variance of the noisy measurements and $\mathbf{S}_{\mathbf{J}}$ is the actual source variance (prior). The latter, according to the Bayesian formulation, is equal to the identity matrix. Therefore, the variance of the estimated current density can be expressed as

$$
\mathbf{S}_{\hat{\mathbf{J}}}=\mathbf{T S}_{\boldsymbol{\Phi}} \mathbf{T}^{T}=\mathbf{T}\left(\mathbf{K} \mathbf{K}^{T}+\alpha \mathbf{H}\right) \mathbf{T}^{T}=\mathbf{K}^{T}\left[\mathbf{K} \mathbf{K}^{T}+\alpha \mathbf{H}\right]^{+} \mathbf{K}
$$

Finally, sLORETA is given by the estimates of standardized current density power:

$$
\sigma_{v}^{T} \sigma_{v}=\hat{j}_{v}^{T}\left[S_{\hat{j}}\right]_{v}^{-1} \hat{j}_{v}
$$

where $\left[S_{\hat{\jmath}}\right]_{v}$ is the $v$ th $3 \times 3$ diagonal matrix in $\left[S_{\hat{\jmath}}\right]$. As for the localization accuracy, sLORETA has zero localization error in ideal (no-noise) conditions and a lower localization error as compared with both the minimum norm and the Dale methods in the case of noisy measurements [37,45].

The latest algorithm of the LORETA family was eLORETA [46]. It introduces a weight matrix $\mathbf{W}$ which considers the deeper sources more adequately. Therefore, in the case of eLORETA, the matrix $\mathbf{W}$ in Equation (4), is defined as

$$
\mathbf{W}_{v}=\left[\mathbf{K}_{v}^{T}\left(\mathbf{K} \mathbf{W}^{-1} \mathbf{K}^{T}+\alpha \mathbf{H}\right)^{+} \mathbf{K}_{v}\right]^{1 / 2}
$$

The matrix $\mathbf{W}_{v} \in R^{3 \times 3}$ is the $v$ th diagonal subblock of $\mathbf{W}$. The complete mathematical formulation of the three algorithms is reported in $[25,40,42,46]$.

eLORETA outperforms sLORETA in terms of resolution and localization error, as reported in [47]. In particular, seventeen subjects underwent a visual stimulus and the corresponding ERP data were collected by 25 electrodes. The active source reconstruction was performed with both sLORETA and eLORETA methods. The comparison between the resulting images at four different time instants showed that eLORETA removes less significant sources and generates less blurred images as compared with SLORETA.

In our paper, the computation of the power current density was conducted by means of the eLORETA algorithm implemented in the LORETA-KEY software (v20200414). The power current density was evaluated by eLORETA for each patient, at time $\mathrm{T} 0$ and $\mathrm{T} 1$, for the following frequency sub-bands: delta $(0.5-4 \mathrm{~Hz})$, theta $(4-8 \mathrm{~Hz})$, alpha $1(8-10.5 \mathrm{~Hz})$, alpha $2(10.5-13 \mathrm{~Hz})$, beta $1(13-18 \mathrm{~Hz})$, and beta $2(18-30 \mathrm{~Hz})$. The comparison between the values at $\mathrm{T} 0$ and $\mathrm{T} 1$ was carried out by grouping the eLORETA solutions by frontal, occipital, parietal and temporal lobes.

\section{Results}

The methodology explained in Section 2.3 was applied to the EEG recordings and produced the following results. The EEG preprocessing and the grouping of power current density values according to the four regions of interest were executed with Matlab (R2018a). A statistical analysis was carried out for determining whether the differences between values at $\mathrm{T} 0$ and $\mathrm{T} 1$ were significant. For this purpose, the Wilcoxon rank sum test [48] was performed under the null hypothesis that, for each patient, the medians of the current density values at time T0 do not differ from those at time T1. The significance level was set at $5 \%$, which means that there is a $5 \%$ risk of concluding that a difference exists when there is no actual difference. So, the difference between T0 and T1 is statistically significant when the $p$-value is less than 0.05 . Tables A1-A3 (see Appendix A) report the p-values resulting from the statistical analysis for each sub-band and each region of interest. F. L., O. L., P. L., and T. L. stand for Frontal Lobe, Occipital Lobe, Parietal Lobe, Temporal Lobe, respectively. The p-values statistically significant which are consistent with the expected results are highlighted 
in gray. Patient 03 shows a widespread increase of power density in delta and theta bands, and a decrease in alpha 1 (parietal region) and beta 2 (temporal lobe) bands. Patient 32 exhibits a greater activation of delta sources in all regions; an increasing power in theta band in the occipital, parietal, and temporal lobes; and a lower activity in alpha 1, alpha 2, and beta 1 bands in the frontal lobe and in beta 2 band in the frontal and occipital lobes. Patient 41 shows a greater power in delta (occipital and parietal areas) and theta (occipital and temporal regions) bands, and a lower activation in alpha 1 (frontal lobe), alpha 2 (frontal, parietal and temporal lobes), beta 1, and beta 2 bands in all lobes. Patients 51 and 71 reveal a widespread decrease of power density for alpha 1, alpha 2, beta 1, and beta 2 bands. As for patient 164, the results are the same except for the parietal lobe in alpha 1 band: in this case the power density increases. Patient 180 displays a widespread greater power in delta and theta bands. Patient 184 shows an increased activation in delta (temporal lobe) and theta (parietal and temporal lobes) bands; the power density decreases in the frontal and occipital regions for alpha 1 and alpha 2 bands, in the occipital lobe for beta 1 band, in the frontal, occipital, and parietal lobe for beta 2 band. The bar graph in Figure 1 summarizes the statistically significant results highlighted in gray in Tables A1-A3. The graph reveals that most significant variations were detected in higher frequency bands. In particular, six patients show a decreasing power density in alpha 1 and alpha 2 (frontal lobe) bands, in addition to beta 2 (frontal and occipital lobes) band. As for delta and theta bands, the power density increases in four subjects at most, except for the temporal lobe in theta band: in this case, the increase is detected in five patients. Figures 2-9 show the boxplots of the power density values of each patient at time T0 and T1, for each frequency sub-band and each region of interest. From the analysis of the results, our hypothesis is that the outcome not consistent with previous findings are due to the passage from $\mathrm{MCI}$ to a mild $\mathrm{AD}$ condition. Therefore, the not yet severe stage of the disease, together with the inter-subject variability, could lead to the above-mentioned discrepancy of some outcome.

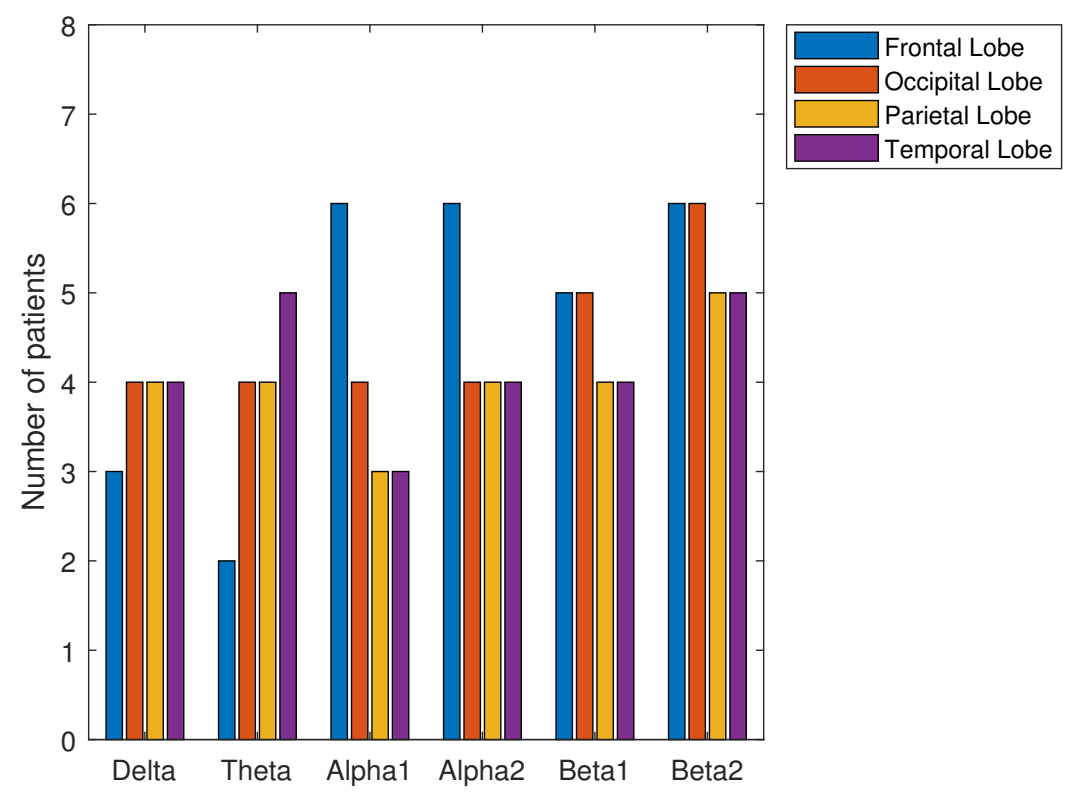

Figure 1. Bar graph of the statistically significant results highlighted in gray in Tables A1-A3. 


\section{Pt 03}
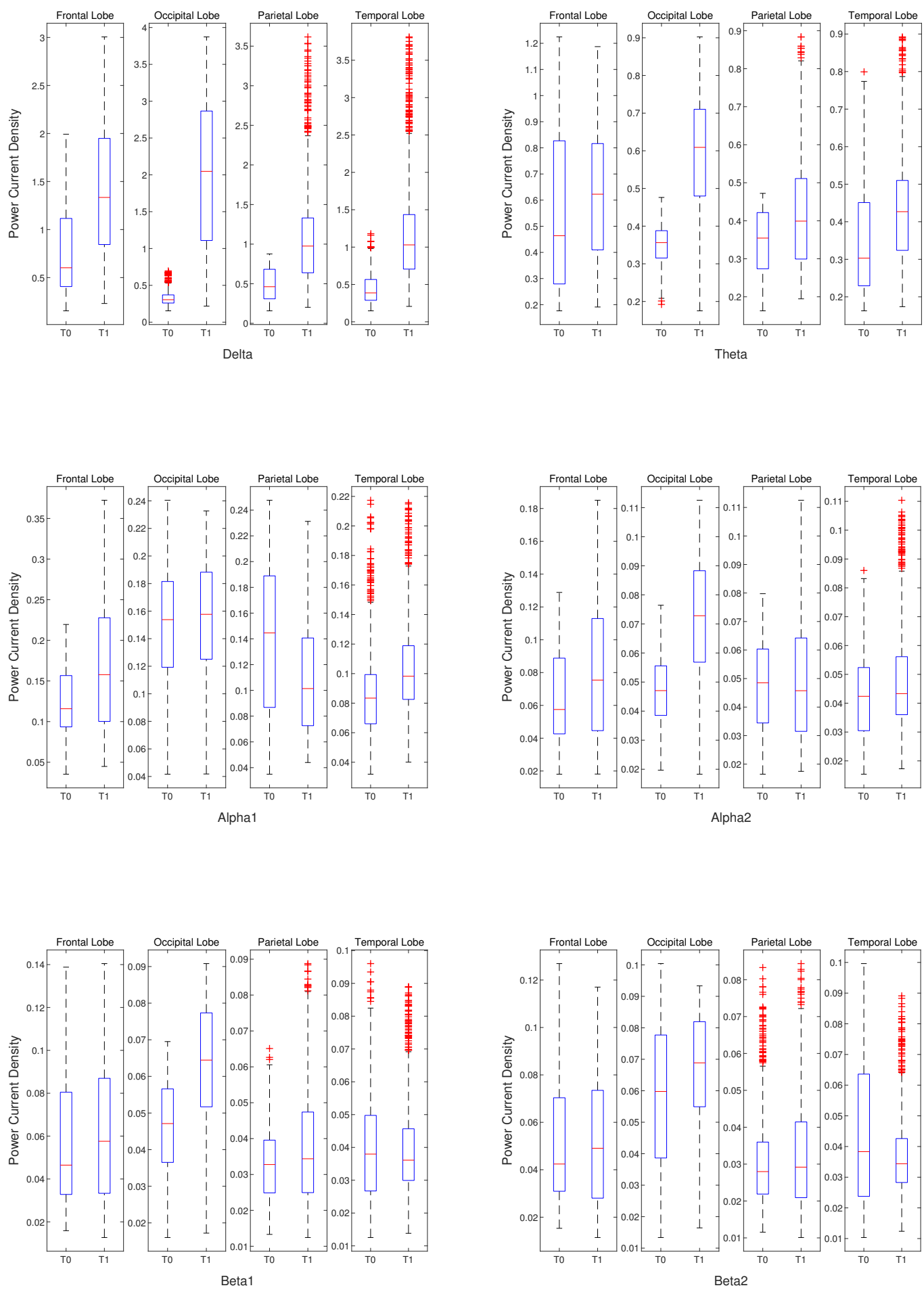

Figure 2. Boxplot of the power current density of patient 03 at time $\mathrm{T} 0$ and $\mathrm{T} 1 \mathrm{for}$ each frequency sub-band and each region of interest (frontal, occipital, parietal, and temporal). 


\section{Pt 32}
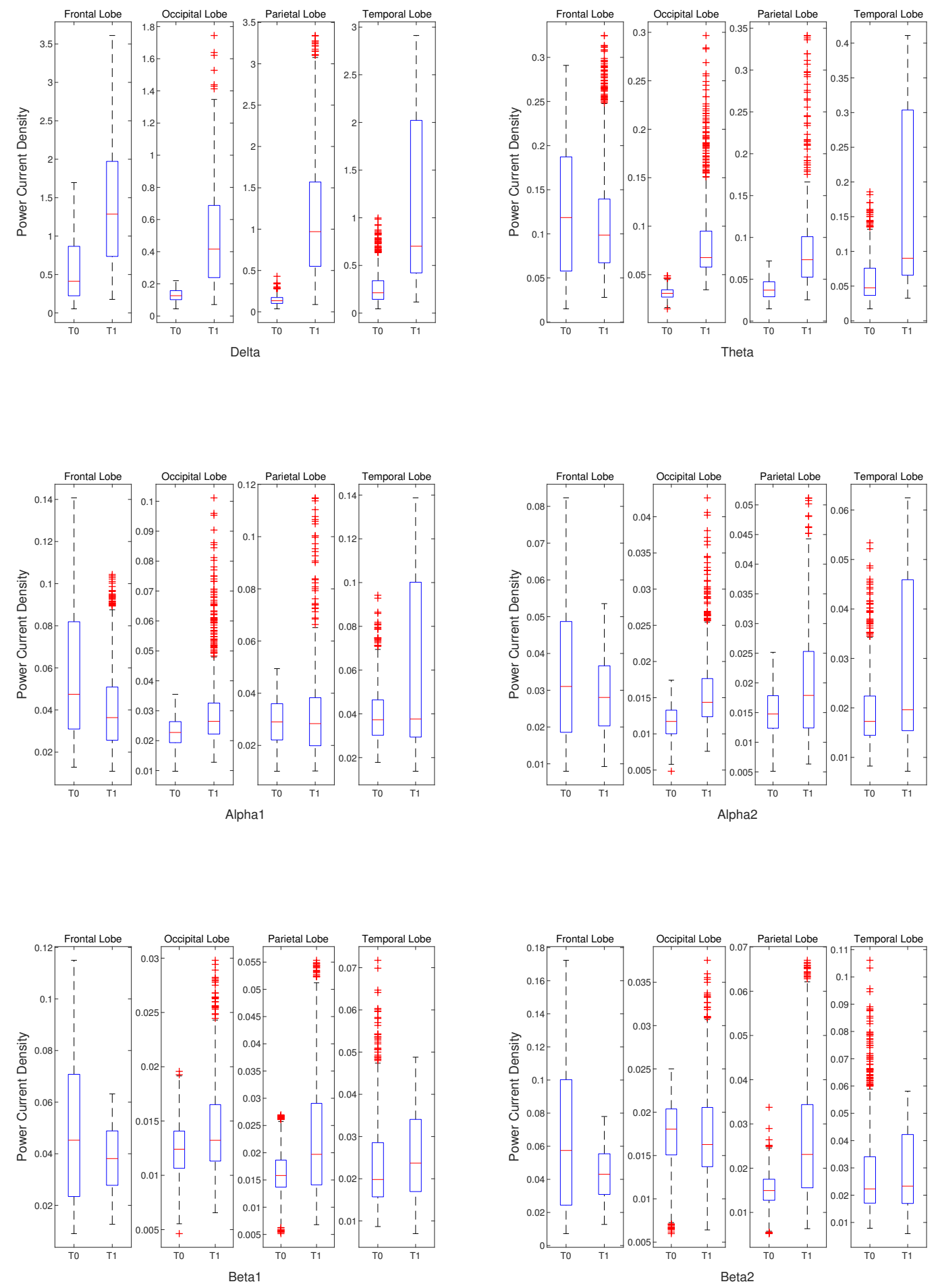

Figure 3. Boxplot of the power current density of patient 32 at time T0 and T1 for each frequency sub-band and each region of interest (frontal, occipital, parietal, and temporal). 


\section{Pt 41}
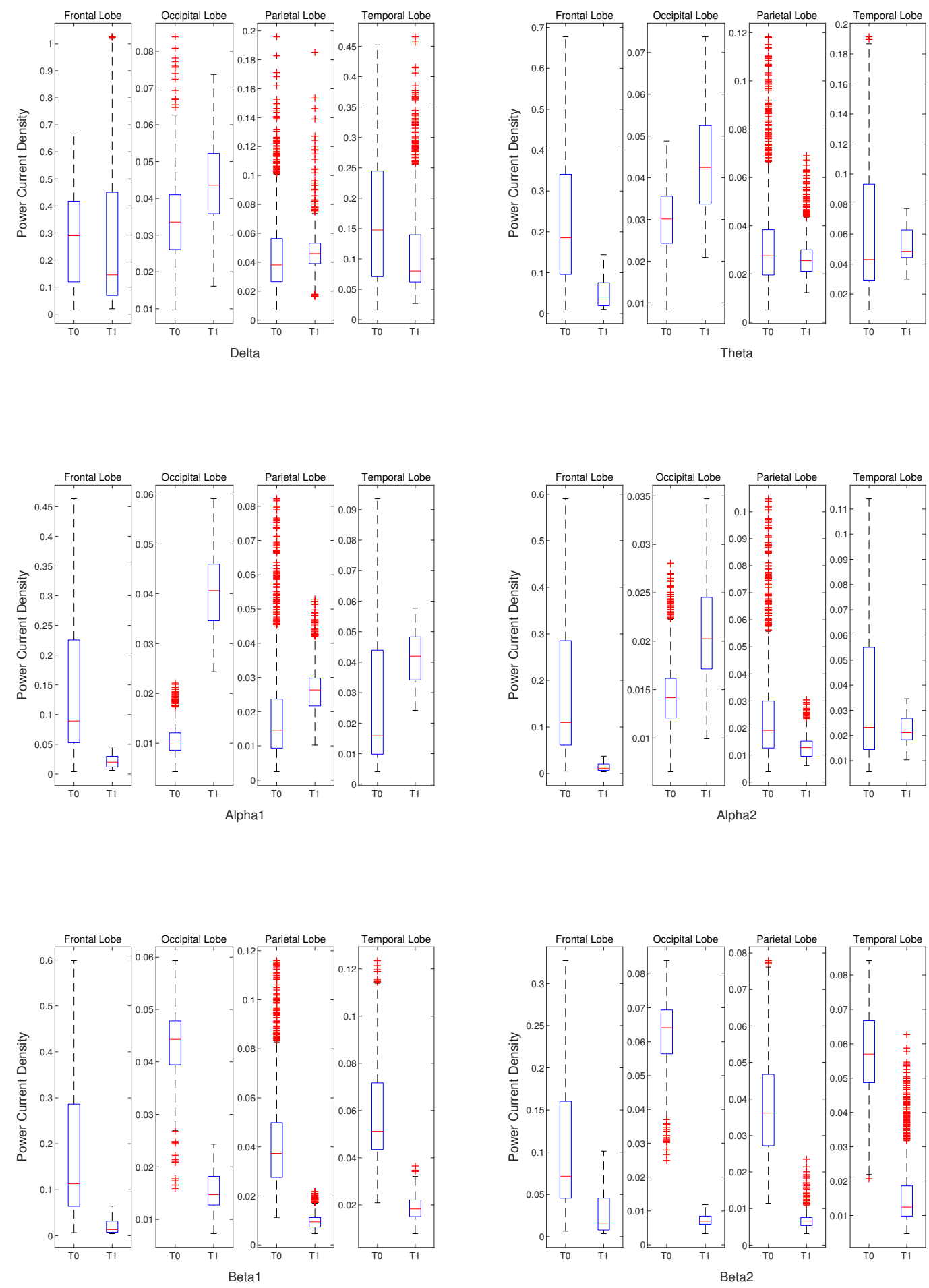

Figure 4. Boxplot of the power current density of patient 41 at time T0 and T1 for each frequency sub-band and each region of interest (frontal, occipital, parietal, and temporal). 


\section{Pt 51}
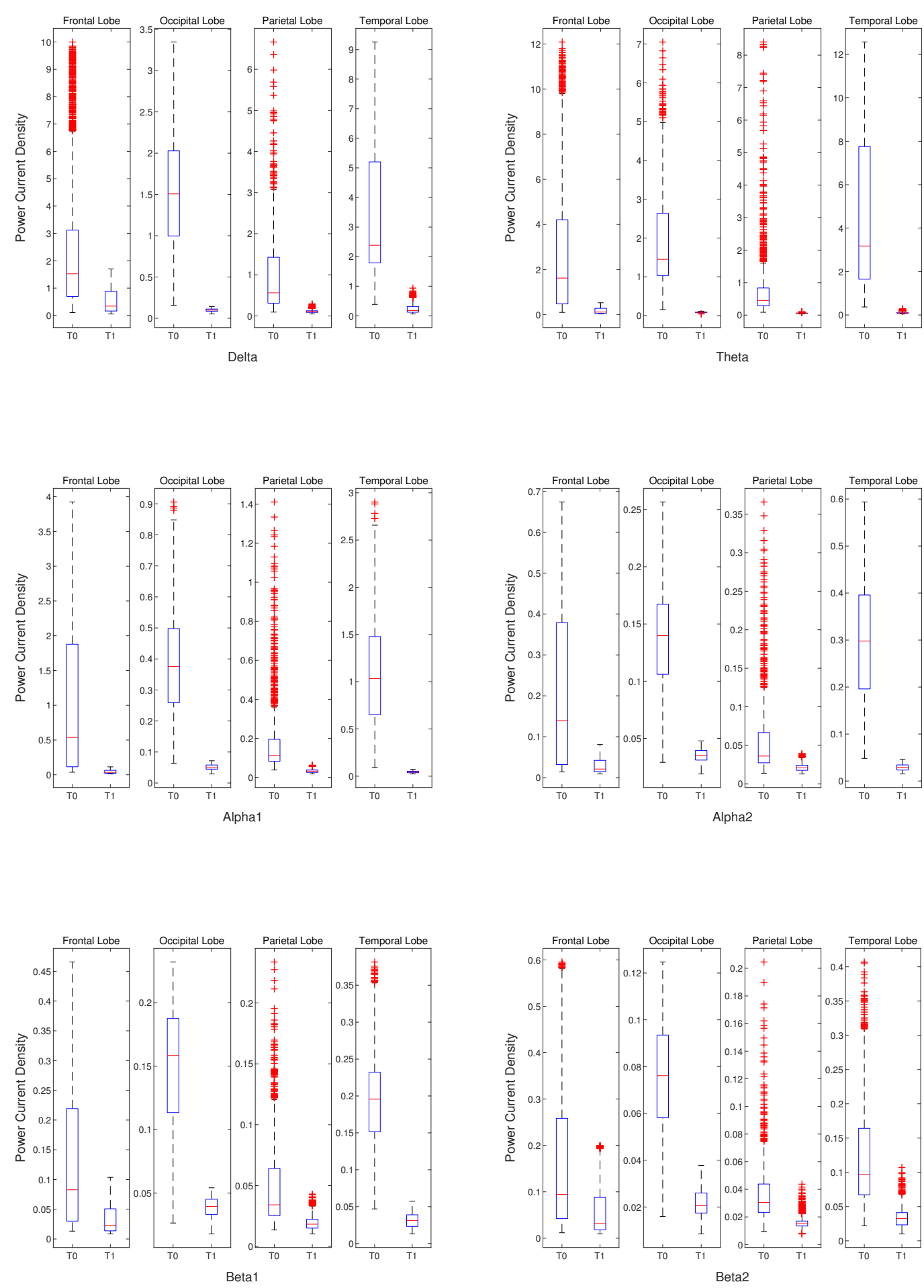

Figure 5. Boxplot of the power current density of patient 51 at time $\mathrm{T} 0$ and $\mathrm{T} 1 \mathrm{for}$ each frequency sub-band and each region of interest (frontal, occipital, parietal, and temporal). 


\section{Pt 71}
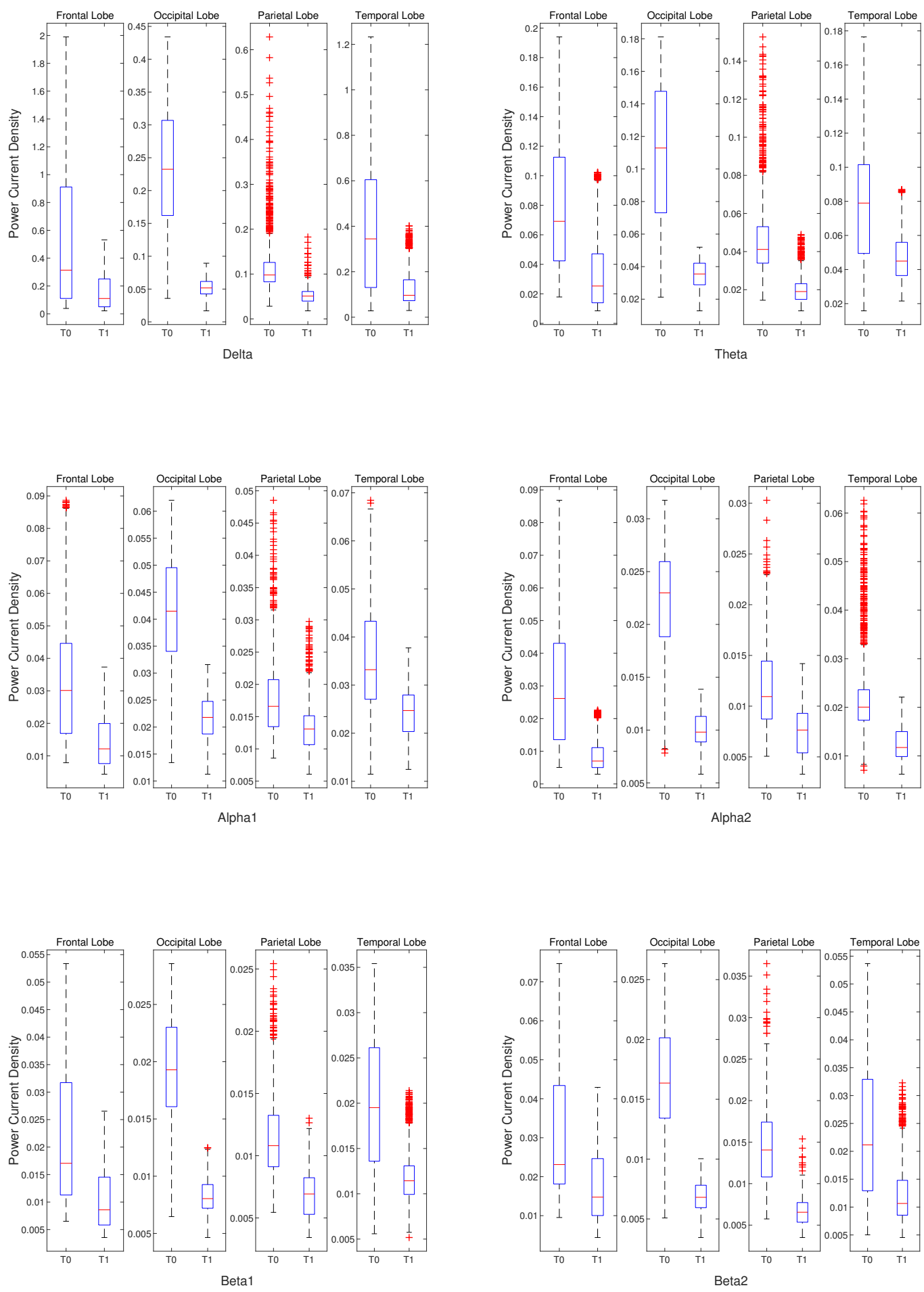

Figure 6. Boxplot of the power current density of patient 71 at time $\mathrm{T} 0$ and $\mathrm{T} 1 \mathrm{for}$ each frequency sub-band and each region of interest (frontal, occipital, parietal, and temporal). 


\section{Pt 164}
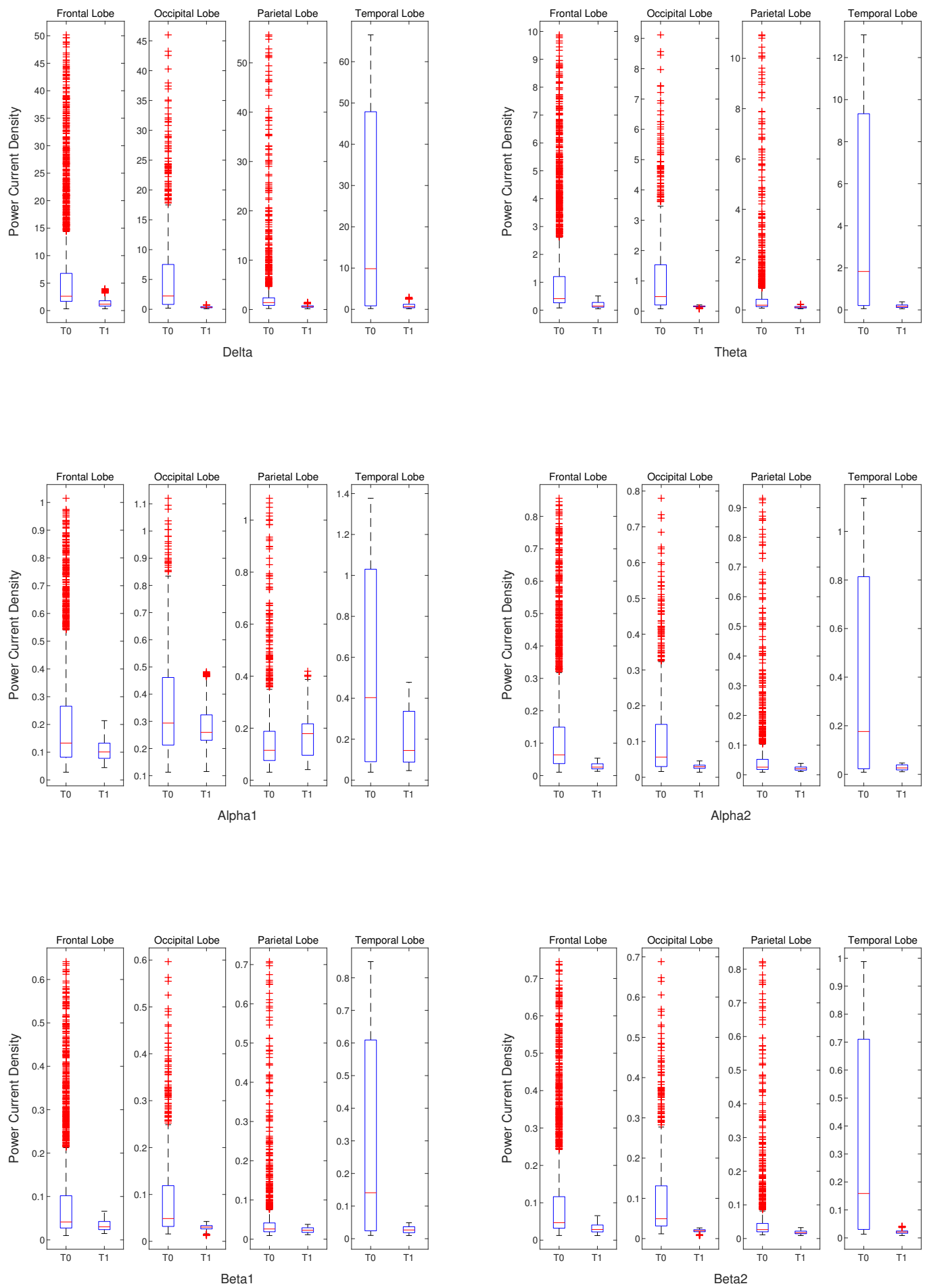

Figure 7. Boxplot of the power current density of patient 164 at time $\mathrm{T} 0$ and $\mathrm{T} 1$ for each frequency sub-band and each region of interest (frontal, occipital, parietal, and temporal). 
Pt 180
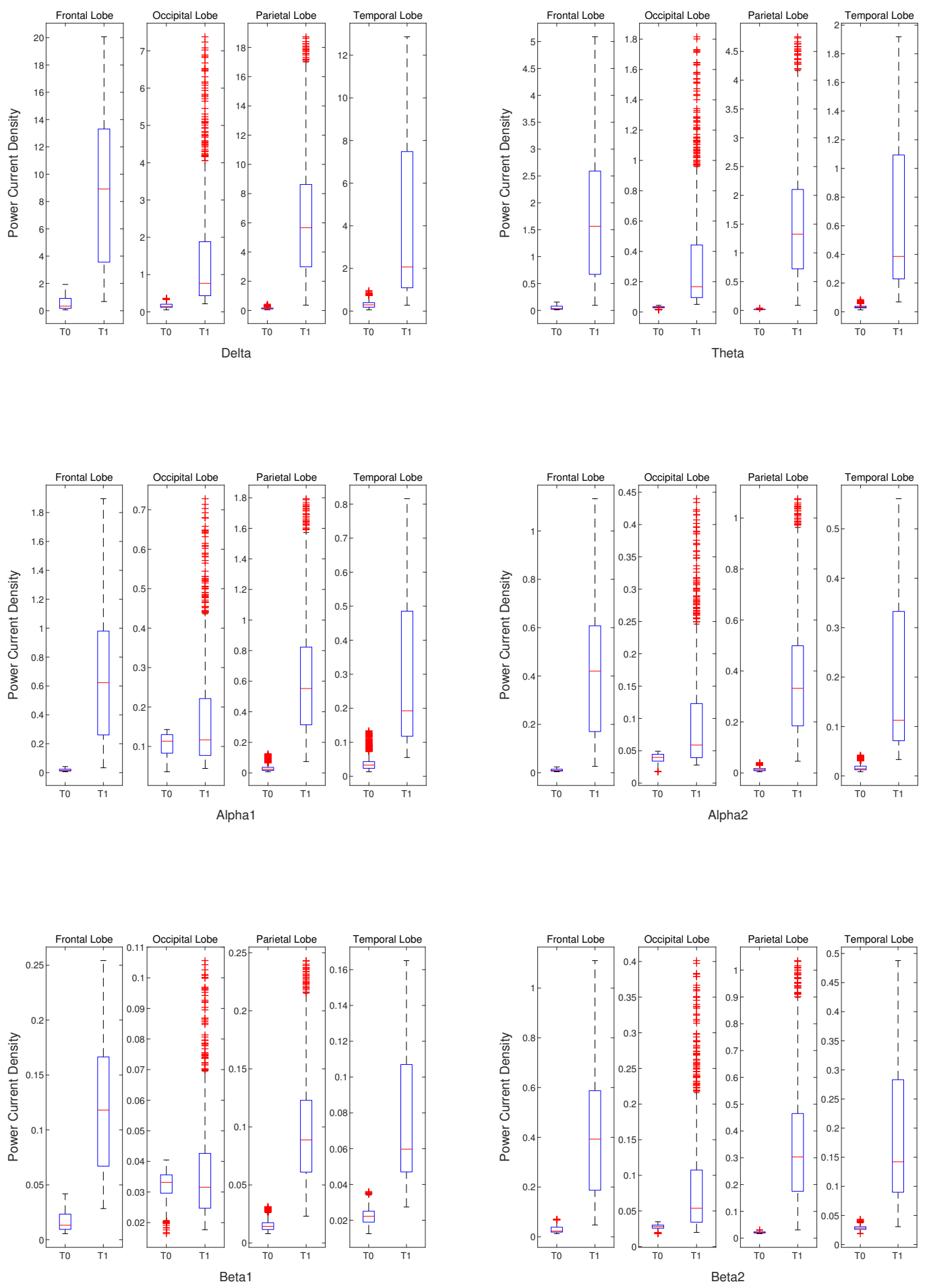

Figure 8. Boxplot of the power current density of patient 180 at time T0 and $\mathrm{T} 1$ for each frequency sub-band and each region of interest (frontal, occipital, parietal, and temporal). 
Pt 184
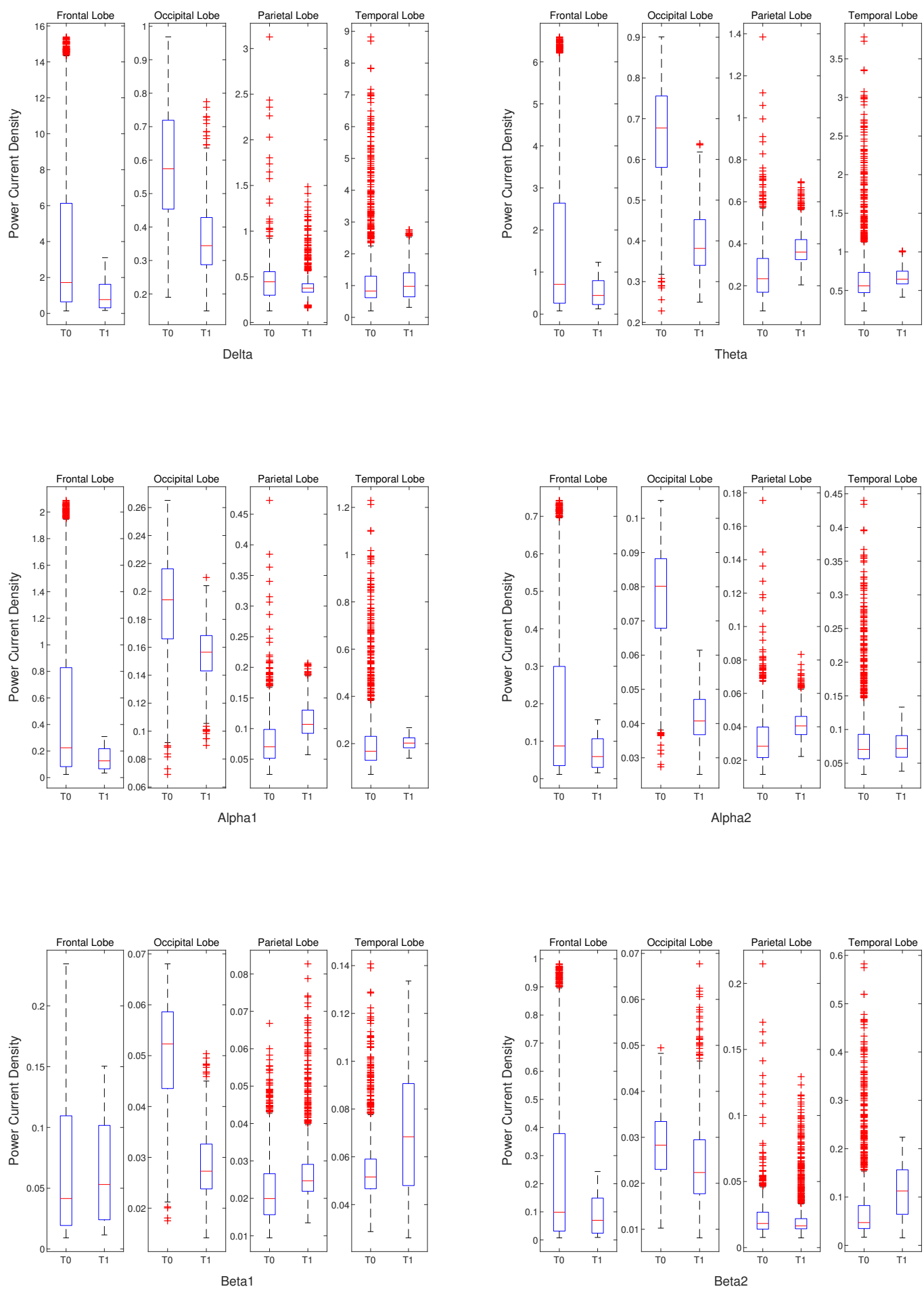

Figure 9. Boxplot of the power current density of patient 184 at time $\mathrm{T} 0$ and $\mathrm{T} 1$ for each frequency sub-band and each region of interest (frontal, occipital, parietal, and temporal).

\section{Discussion and Conclusions}

Alzheimer's disease is a neurological disorder which is the most common cause of dementia. As there is no cure for AD, early diagnosis is very important. In fact, a pharmacological treatment 
in the early stage (MCI) can slow down the evolution of the disease. The potential of EEG as a tool for studying AD has been widely explored and proved in the last years. In fact, the use of the EEG is advisable as compared to imaging techniques because it is easy-to-use, not expensive, comfortable, and safe for the patient.

Over the years, several studies have revealed that EEG signals of AD patients become slower, meaning that the spectral power is shifted towards lower frequencies [49]. In our paper, we conducted a longitudinal study involving eight patients who converted from $\mathrm{MCI}$ to $\mathrm{AD}$ after four months. The doctors made the diagnosis according to the MoCA scores. The novelty is that the spectral power analysis was carried out by means of eLORETA algorithm, which should provide a better source localization accuracy compared to LORETA. The previous works, both cross-sectional and longitudinal, were all carried out using LORETA [26-36]. The time period of follow-up was relatively short, so the condition at time $\mathrm{T} 1$ should be considered as slight worse in comparison with $\mathrm{MCI}$ condition at time T0. Finally, unlike the three longitudinal studies reported in [34-36], whose results are at group level, our work wants to investigate whether resting state EEG sources can be a marker to follow the progression of the disease in a single AD subject. In our study, five patients $(03,32,41,180$, and 184) out of eight showed an increasing power in delta and theta bands. All patients, except for 180, exhibited a lower activation in alpha 1 and beta 2 bands. Finally, all patients, except for 03 and 180, revealed a decreased power in alpha 2 and beta 1 bands. Most of our findings are consistent with those of previous studies. On the other hand, the discrepancy of some outcomes could be related to the not yet severe stage of the disease at time T1. This topic needs to be further explored. As for the future development, it could be interesting to apply the eLORETA method to high-density EEG, which should improve the source localization accuracy [50]. In addition, it would be advisable to test the method on a larger number of patients for the validation of results. In order to further confirm the better performance of eLORETA as compared to both LORETA and SLORETA, as already proved in [46,47], a comparative methodological study could be carried out. Moreover, as in recent years several new algorithms for solving the EEG inverse problem have been developed, a comparison between them and eLORETA would be essential for testing the eLORETA effectiveness [51]. Finally, the combination of source reconstruction with complex network analysis could also provide a further instrument for a better understanding of the evolution of the disease. In conclusion, our work could represent a first step for more detailed investigations, in order to make the analysis of power current density a valid tool for evaluating the cognitive decline in AD.

Author Contributions: Conceptualization, S.D. and F.L.F.; Methodology, S.D. and F.L.F.; Formal Analysis, S.D.; Software, S.D.; Project administration, F.L.F.; Writing—original draft preparation, S.D.; Writing-review and editing, F.L.F.; Supervision, F.L.F. All authors have read and agreed to the published version of the manuscript.

Funding: This research received no external funding.

Acknowledgments: The authors thank the doctors of IRCCS Centro Neurolesi Bonino-Pulejo of Messina (Italy) for their insightful comments and suggestions.

Conflicts of Interest: The authors declare no conflict of interest.

\section{Appendix A}

Table A1. $p$-values resulting from the Wilcoxon rank sum test for delta and theta sub-bands.

\begin{tabular}{ccccccccc}
\hline \multirow{2}{*}{ Patient ID } & \multicolumn{9}{c}{ Delta } \\
\cline { 2 - 9 } & F. L. & O. L. & P. L. & T. L. & F. L. & O. L. & Theta \\
\hline Pt 03 & $8.75 \times 10^{-222}$ & $1.12 \times 10^{-235}$ & $2.82 \times 10^{-180}$ & $7.55 \times 10^{-264}$ & $1.54 \times 10^{-23}$ & $1.49 \times 10^{-161}$ & $5.13 \times 10^{-13}$ & $4.16 \times 10^{-48}$ \\
Pt 32 & $2.38 \times 10^{-301}$ & $6.10 \times 10^{-207}$ & 0 & $2.12 \times 10^{-240}$ & $2.73 \times 10^{-8}$ & $2.90 \times 10^{-244}$ & $1.82 \times 10^{-234}$ & $2.54 \times 10^{-160}$ \\
Pt 41 & $3.22 \times 10^{-14}$ & $2.78 \times 10^{-55}$ & $2.37 \times 10^{-18}$ & $3.382 \times 10^{-29}$ & 0 & $6.27 \times 10^{-101}$ & $8.97 \times 10^{-6}$ & $5.55 \times 10^{-5}$ \\
Pt 51 & 0 & $4.60 \times 10^{-250}$ & 0 & 0 & 0 & $4.60 \times 10^{-250}$ & 0 & 0 \\
Pt 71 & $8.15 \times 10^{-184}$ & $2.31 \times 10^{-232}$ & $4.56 \times 10^{-303}$ & $1.37 \times 10^{-148}$ & $7.94 \times 10^{-319}$ & $5.59 \times 10^{-222}$ & $6.23 \times 10^{-309}$ & $1.13 \times 10^{-134}$ \\
Pt 164 & $3.87 \times 10^{-261}$ & $9.26 \times 10^{-214}$ & $4.17 \times 10^{-210}$ & $1.55 \times 10^{-147}$ & 0 & $1.39 \times 10^{-168}$ & $4.16 \times 10^{-189}$ & $2.62 \times 10^{-171}$ \\
Pt 180 & 0 & $2.66 \times 10^{-242}$ & 0 & 0 & 0 & $4.60 \times 10^{-250}$ & 0 \\
Pt 184 & $1.05 \times 10^{-126}$ & $7.47 \times 10^{-124}$ & $7.11 \times 10^{-15}$ & $3.80 \times 10^{-4}$ & $1.15 \times 10^{-44}$ & $3.22 \times 10^{-187}$ & $4.31 \times 10^{-131}$ & $6.08 \times 10^{-30}$ \\
\hline
\end{tabular}


Table A2. p-values resulting from the Wilcoxon rank sum test for alpha 1 and alpha 2 sub-bands.

\begin{tabular}{ccccccccc}
\hline \multirow{2}{*}{ Patient ID } & \multicolumn{9}{c}{ Alpha 1 } & \multicolumn{3}{c}{ Alpha 2 } \\
\cline { 2 - 8 } & F. L. & O. L. & P. L. & T. L. & F. L. & O. L. & P. L. \\
\hline Pt 03 & $7.81 \times 10^{-70}$ & 0.0511 & $3.42 \times 10^{-38}$ & $1.23 \times 10^{-47}$ & $4.07 \times 10^{-27}$ & $4.38 \times 10^{-111}$ & 0.4836 & $8.77 \times 10^{-8}$ \\
Pt 32 & $2.30 \times 10^{-63}$ & $7.24 \times 10^{-36}$ & 0.6518 & $2.06 \times 10^{-15}$ & $3.78 \times 10^{-14}$ & $2.45 \times 10^{-69}$ & $3.65 \times 10^{-27}$ & $2.24 \times 10^{-33}$ \\
Pt 41 & 0 & $4.60 \times 10^{-250}$ & $1.37 \times 10^{-97}$ & $5.93 \times 10^{-88}$ & 0 & $2.07 \times 10^{-118}$ & $8.614 \times 10^{-90}$ & $5.95 \times 10^{-5}$ \\
Pt 51 & 0 & $8.09 \times 10^{-250}$ & 0 & 0 & 0 & $5.44 \times 10^{-242}$ & $4.74 \times 10^{-242}$ & 0 \\
Pt 71 & $1.69 \times 10^{-302}$ & $4.72 \times 10^{-206}$ & $5.86 \times 10^{-90}$ & $1.25 \times 10^{-150}$ & 0 & $2.97 \times 10^{-225}$ & $1.63 \times 10^{-164}$ & $1.55 \times 10^{-248}$ \\
Pt 164 & $1.46 \times 10^{-61}$ & $5.18 \times 10^{-7}$ & $2.09 \times 10^{-18}$ & $2.84 \times 10^{-18}$ & $5.62 \times 10^{-317}$ & $5.06 \times 10^{-81}$ & $1.50 \times 10^{-39}$ & $6.83 \times 10^{-74}$ \\
Pt 180 & 0 & $1.81 \times 10^{-9}$ & 0 & 0 & 0 & $1.32 \times 10^{-75}$ & 0 \\
Pt 184 & $1.45 \times 10^{-68}$ & $4.03 \times 10^{-92}$ & $2.72 \times 10^{-127}$ & $1.16 \times 10^{-31}$ & $4.80 \times 10^{-42}$ & $1.28 \times 10^{-217}$ & $2.05 \times 10^{-90}$ & 0 \\
\hline
\end{tabular}

Table A3. p-values resulting from the Wilcoxon rank sum test for beta 1 and beta 2 sub-bands.

\begin{tabular}{ccccccccc}
\hline \multirow{2}{*}{ Patient ID } & \multicolumn{9}{c}{ Beta 1 } & \multicolumn{3}{c}{ Beta 2 } \\
\cline { 2 - 8 } & F. L. & O. L. & P. L. & T. L. & F. L. & O. L. & P. L. \\
\hline Pt 03 & 0.0015 & $5.75 \times 10^{-79}$ & $8.44 \times 10^{-9}$ & 0.8607 & 0.4786 & $1.66 \times 10^{-11}$ & 0.0279 & $4.77 \times 10^{-6}$ \\
Pt 32 & $1.02 \times 10^{-21}$ & $8.53 \times 10^{-13}$ & $7.93 \times 10^{-40}$ & $5.12 \times 10^{-11}$ & $1.17 \times 10^{-34}$ & 0.0037 & $3.85 \times 10^{-105}$ & 0.0128 \\
Pt 41 & 0 & $9.77 \times 10^{-248}$ & 0 & 0 & 0 & $4.60 \times 10^{-250}$ & 0 \\
Pt 51 & $7.31 \times 10^{-268}$ & $3.02 \times 10^{-228}$ & $6.65 \times 10^{-241}$ & 0 & $1.83 \times 10^{-191}$ & $6.56 \times 10^{-229}$ & $9.64 \times 10^{-273}$ & $1.41 \times 10^{-321}$ \\
Pt 71 & $6.83 \times 10^{-260}$ & $6.19 \times 10^{-232}$ & $6.19 \times 10^{-232}$ & $1.02 \times 10^{-176}$ & $1.58 \times 10^{-196}$ & $9.14 \times 10^{-229}$ & 0 \\
Pt 164 & $2.77 \times 10^{-80}$ & $4.62 \times 10^{-87}$ & $3.14 \times 10^{-19}$ & $1.23 \times 10^{-68}$ & $3.13 \times 10^{-181}$ & $8.86 \times 10^{-214}$ & $1.23 \times 10^{-132}$ & $2.09 \times 10^{-141}$ \\
Pt 180 & 0 & 0.4370 & 0 & 0 & 0 & $1.84 \times 10^{-149}$ & 0 \\
Pt 184 & 0.0016 & $5.54 \times 10^{-200}$ & $2.60 \times 10^{-55}$ & $6.59 \times 10^{-45}$ & $1.45 \times 10^{-33}$ & $1.05 \times 10^{-26}$ & $2.67 \times 10^{-4}$ & $1.47 \times 10^{-78}$ \\
\hline
\end{tabular}

\section{References}

1. Weintraub, S.; Wicklund, A.H.; Salmon, D.P. The neuropsychological profile of Alzheimer disease. Cold Spring Harb. Perspect. Med. 2012, 2, a006171. [CrossRef]

2. Sperling, R.A.; Aisen, P.S.; Beckett, L.A.; Bennett, D.A.; Craft, S.; Fagan, A.M.; Iwatsubo, T.; Jack, C.R., Jr.; Kaye, J.; Montine, T.J.; et al. Toward defining the preclinical stages of Alzheimer's disease: Recommendations from the National Institute on Aging-Alzheimer's Association workgroups on diagnostic guidelines for Alzheimer's disease. Alzheimers Dement. 2011, 7, 280-292. [CrossRef]

3. Albert, M.S.; DeKosky, S.T.; Dickson, D.; Dubois, B.; Feldman, H.H.; Fox, N.C.; Gamst, A.; Holtzman, D.M.; Jagust, W.J.; Petersen, R.C.; et al. The diagnosis of mild cognitive impairment due to Alzheimer's disease: Recommendations from the National Institute on Aging-Alzheimer's Association workgroups on diagnostic guidelines for Alzheimer's disease. Alzheimers Dement. 2011, 7, 270-279. [CrossRef]

4. McKhann, G.M.; Knopman, D.S.; Chertkow, H.; Hyman, B.T.; Jack, C.R., Jr.; Kawas, C.H.; Klunk, W.E.; Koroshetz, W.J.; Manly, J.J.; Mayeux, R.; et al. The diagnosis of dementia due to Alzheimer's disease: Recommendations from the National Institute on Aging-Alzheimer's Association workgroups on diagnostic guidelines for Alzheimer's disease. Alzheimers Dement. 2011, 7, 263-269. [CrossRef]

5. Rossini, P.; Di Iorio, R.; Vecchio, F.; Anfossi, M.; Babiloni, C.; Bozzali, M.; Bruni, A.; Cappa, S.; Escudero, J.; Fraga, F.; et al. Early diagnosis of alzheimer's disease: The role of biomarkers including advanced EEG signals analysis. An IFCN-sponsored panel of Experts. Clin. Neurophysiol. 2020, 131, 1287-1310. [CrossRef]

6. McGinnis, S.M. Neuroimaging in neurodegenerative dementias. In Seminars in Neurology; Thieme Medical Publishers: New York, NY, USA, 2012; Volume 32, pp. 347-360.

7. Bozzali, M.; Serra, L.; Cercignani, M. Quantitative MRI to understand Alzheimer's disease pathophysiology. Curr. Opin. Neurol. 2016, 29, 437-444. [CrossRef] [PubMed]

8. Iaccarino, L.; Chiotis, K.; Alongi, P.; Almkvist, O.; Wall, A.; Cerami, C.; Bettinardi, V.; Gianolli, L.; Nordberg, A.; Perani, D. A cross-validation of FDG-and amyloid-PET biomarkers in mild cognitive impairment for the risk prediction to dementia due to Alzheimer's disease in a clinical setting. J. Alzheimers Dis. 2017, 59, 603-614. [CrossRef] [PubMed]

9. Pillai, J.; Sperling, M.R. Interictal EEG and the diagnosis of epilepsy. Epilepsia 2006, 47, 14-22. [CrossRef] [PubMed]

10. Mammone, N.; De Salvo, S.; Ieracitano, C.; Marino, S.; Cartella, E.; Bramanti, A.; Giorgianni, R.; Morabito, F.C. Compressibility of High-Density EEG Signals in Stroke Patients. Sensors 2018, 18, 4107. [CrossRef] [PubMed]

11. Wolters, C.H.; Anwander, A.; Tricoche, X.; Weinstein, D.; Koch, M.A.; Macleod, R.S. Influence of tissue conductivity anisotropy on EEG/MEG field and return current computation in a realistic head model: 
A simulation and visualization study using high-resolution finite element modeling. NeuroImage 2006, 30, 813-826. [CrossRef] [PubMed]

12. Morabito, F.C.; Campolo, M.; Ieracitano, C.; Ebadi, J.M.; Bonanno, L.; Bramanti, A.; Desalvo, S.; Mammone, N.; Bramanti, P. Deep convolutional neural networks for classification of mild cognitive impaired and Alzheimer's disease patients from scalp EEG recordings. In Proceedings of the 2016 IEEE 2nd International Forum on Research and Technologies for Society and Industry Leveraging a better tomorrow (RTSI), Bologna, Italy, 7-9 September 2016; pp. 1-6.

13. Mammone, N.; Ieracitano, C.; Adeli, H.; Bramanti, A.; Morabito, F.C. Permutation Jaccard distance-based hierarchical clustering to estimate EEG network density modifications in MCI subjects. IEEE Trans. Neural Networks Learn. Syst. 2018, 29, 5122-5135. [CrossRef] [PubMed]

14. Mammone, N.; De Salvo, S.; Bonanno, L.; Ieracitano, C.; Marino, S.; Marra, A.; Bramanti, A.; Morabito, F.C. Brain network analysis of compressive sensed high-density EEG signals in AD and MCI subjects. IEEE Trans. Ind. Inform. 2018, 15, 527-536. [CrossRef]

15. La Foresta, F.; Morabito, F.C.; Marino, S.; Dattola, S. High-density EEG signal processing based on active-source reconstruction for brain network analysis in alzheimer's disease. Electronics 2019, 8, 1031. [CrossRef]

16. Ieracitano, C.; Mammone, N.; Hussain, A.; Morabito, F.C. A novel multi-modal machine learning based approach for automatic classification of EEG recordings in dementia. Neural Netw. 2020, 123, 176-190. [CrossRef] [PubMed]

17. Huang, C.; Wahlund, L.O.; Dierks, T.; Julin, P.; Winblad, B.; Jelic, V. Discrimination of Alzheimer's disease and mild cognitive impairment by equivalent EEG sources: A cross-sectional and longitudinal study. Clin. Neurophysiol. 2000, 111, 1961-1967. [CrossRef]

18. Moretti, D.V.; Babiloni, C.; Binetti, G.; Cassetta, E.; Dal Forno, G.; Ferreric, F.; Ferri, R.; Lanuzza, B.; Miniussi, C.; Nobili, F.; et al. Individual analysis of EEG frequency and band power in mild Alzheimer's disease. Clin. Neurophysiol. 2004, 115, 299-308. [CrossRef]

19. Van der Hiele, K.; Vein, A.; Reijntjes, R.; Westendorp, R.; Bollen, E.; Van Buchem, M.; Van Dijk, J.; Middelkoop, H. EEG correlates in the spectrum of cognitive decline. Clin. Neurophysiol. 2007, 118, 1931-1939. [CrossRef]

20. Czigler, B.; Csikós, D.; Hidasi, Z.; Gaál, Z.A.; Csibri, É.; Kiss, É.; Salacz, P.; Molnár, M. Quantitative EEG in early Alzheimer's disease patients-power spectrum and complexity features. Int. J. Psychophysiol. 2008, 68, 75-80. [CrossRef]

21. Gasser, U.S.; Rousson, V.; Hentschel, F.; Sattel, H.; Gasser, T. Alzheimer disease versus mixed dementias: An EEG perspective. Clin. Neurophysiol. 2008, 119, 2255-2259. [CrossRef]

22. Hsiao, F.J.; Wang, Y.J.; Yan, S.H.; Chen, W.T.; Lin, Y.Y. Altered oscillation and synchronization of default-mode network activity in mild Alzheimer's disease compared to mild cognitive impairment: An electrophysiological study. PLoS ONE 2013, 8, e68792. [CrossRef]

23. Jeong, J. EEG dynamics in patients with Alzheimer's disease. Clin. Neurophysiol. 2004, 115, 1490-1505. [CrossRef] [PubMed]

24. Babiloni, C.; Lizio, R.; Marzano, N.; Capotosto, P.; Soricelli, A.; Triggiani, A.I.; Cordone, S.; Gesualdo, L.; Del Percio, C. Brain neural synchronization and functional coupling in Alzheimer's disease as revealed by resting state EEG rhythms. Int. J. Psychophysiol. 2016, 103, 88-102. [CrossRef] [PubMed]

25. Marqui, R.P.; Michel, C.M.; Lehmann, D. Low-resolution electromagnetic tomography-A new method for localizing electrical activity in the brain. Int. J. Psychophysiol. 1994, 18, 49-65. [CrossRef]

26. Babiloni, C.; Binetti, G.; Cassetta, E.; Cerboneschi, D.; Dal Forno, G.; Del Percio, C.; Ferreri, F.; Ferri, R.; Lanuzza, B.; Miniussi, C.; et al. Mapping distributed sources of cortical rhythms in mild Alzheimer's disease. A multicentric EEG study. Neuroimage 2004, 22, 57-67. [CrossRef] [PubMed]

27. Babiloni, C.; Binetti, G.; Cassetta, E.; Dal Forno, G.; Del Percio, C.; Ferreri, F.; Ferri, R.; Frisoni, G.; Hirata, K.; Lanuzza, B.; et al. Sources of cortical rhythms change as a function of cognitive impairment in pathological aging: A multicenter study. Clin. Neurophysiol. 2006, 117, 252-268. [CrossRef] [PubMed]

28. Babiloni, C.; Frisoni, G.B.; Pievani, M.; Vecchio, F.; Lizio, R.; Buttiglione, M.; Geroldi, C.; Fracassi, C.; Eusebi, F.; Ferri, R.; et al. Hippocampal volume and cortical sources of EEG alpha rhythms in mild cognitive impairment and Alzheimer disease. Neuroimage 2009, 44, 123-135. [CrossRef] [PubMed] 
29. Babiloni, C.; Lizio, R.; Carducci, F.; Vecchio, F.; Redolfi, A.; Marino, S.; Tedeschi, G.; Montella, P.; Guizzaro, A.; Esposito, F.; et al. Resting state cortical electroencephalographic rhythms and white matter vascular lesions in subjects with Alzheimer's disease: An Italian multicenter study. J. Alzheimers Dis. 2011, 26, 331-346. [CrossRef]

30. Babiloni, C.; Carducci, F.; Lizio, R.; Vecchio, F.; Baglieri, A.; Bernardini, S.; Cavedo, E.; Bozzao, A.; Buttinelli, C.; Esposito, F.; et al. Resting state cortical electroencephalographic rhythms are related to gray matter volume in subjects with mild cognitive impairment and Alzheimer's disease. Hum. Brain Mapp. 2013, 34, 1427-1446. [CrossRef]

31. Canuet, L.; Tellado, I.; Couceiro, V.; Fraile, C.; Fernandez-Novoa, L.; Ishii, R.; Takeda, M.; Cacabelos, R. Resting-state network disruption and APOE genotype in Alzheimer's disease: A lagged functional connectivity study. PLoS ONE 2012, 7, e46289. [CrossRef]

32. Gianotti, L.R.; Künig, G.; Lehmann, D.; Faber, P.L.; Pascual-Marqui, R.D.; Kochi, K.; Schreiter-Gasser, U. Correlation between disease severity and brain electric LORETA tomography in Alzheimer's disease. Clin. Neurophysiol. 2007, 118, 186-196. [CrossRef]

33. Nishida, K.; Yoshimura, M.; Isotani, T.; Yoshida, T.; Kitaura, Y.; Saito, A.; Mii, H.; Kato, M.; Takekita, Y.; Suwa, A.; et al. Differences in quantitative EEG between frontotemporal dementia and Alzheimer's disease as revealed by LORETA. Clin. Neurophysiol. 2011, 122, 1718-1725. [CrossRef] [PubMed]

34. Rossini, P.; Del Percio, C.; Pasqualetti, P.; Cassetta, E.; Binetti, G.; Dal Forno, G.; Ferreri, F.; Frisoni, G.; Chiovenda, P.; Miniussi, C.; et al. Conversion from mild cognitive impairment to Alzheimer's disease is predicted by sources and coherence of brain electroencephalography rhythms. Neuroscience 2006, 143, 793-803. [CrossRef] [PubMed]

35. Babiloni, C.; Frisoni, G.B.; Vecchio, F.; Lizio, R.; Pievani, M.; Cristina, G.; Fracassi, C.; Vernieri, F.; Rodriguez, G.; Nobili, F.; et al. Stability of clinical condition in mild cognitive impairment is related to cortical sources of alpha rhythms: An electroencephalographic study. Hum. Brain Mapp. 2011, 32, 1916-1931. [CrossRef] [PubMed]

36. Babiloni, C.; Lizio, R.; Del Percio, C.; Marzano, N.; Soricelli, A.; Salvatore, E.; Ferri, R.; Cosentino, F.I.; Tedeschi, G.; Montella, P.; et al. Cortical sources of resting state EEG rhythms are sensitive to the progression of early stage Alzheimer's disease. J. Alzheimers Dis. 2013, 34, 1015-1035. [CrossRef] [PubMed]

37. Hämäläinen, M.S.; Ilmoniemi, R.J. Interpreting magnetic fields of the brain: Minimum norm estimates. Med. Biol. Eng. Comput. 1994, 32, 35-42. [CrossRef]

38. Talairach, J.; Tournoux, P. Co-Planar Stereotaxic Atlas of the Human Brain; Theime: New York, NY, USA, 1988.

39. Collins, D.L.; Neelin, P.; Peters, T.M.; Evans, A.C. Automatic 3D intersubject registration of MR volumetric data in standardized Talairach space. J. Comput. Assist. Tomogr. 1994, 18, 192-205. [CrossRef]

40. Tong, S.; Thakor, N.V. Quantitative EEG Analysis Methods and Clinical Applications; Artech House: Norwood, MA, USA, 2009.

41. Tikhonov, A.N.; Arsenin, V.Y. Solutions of Ill-Posed Problems; Wiley: New York, NY, USA, 1977; pp. 1-30.

42. Pascual-Marqui, R.D. Standardized low-resolution brain electromagnetic tomography (sLORETA): Technical details. Methods Find. Exp. Clin. Pharmacol. 2002, 24, 5-12.

43. Mazziotta, J.; Toga, A.; Evans, A.; Fox, P.; Lancaster, J.; Zilles, K.; Woods, R.; Paus, T.; Simpson, G.; Pike, B.; et al. A probabilistic atlas and reference system for the human brain: International Consortium for Brain Mapping (ICBM). Philos. Trans. R. Soc. Lond. Ser. Biol. Sci. 2001, 356, 1293-1322. [CrossRef]

44. Fuchs, M.; Kastner, J.; Wagner, M.; Hawes, S.; Ebersole, J.S. A standardized boundary element method volume conductor model. Clin. Neurophysiol. 2002, 113, 702-712. [CrossRef]

45. Dale, A.M.; Liu, A.K.; Fischl, B.R.; Buckner, R.L.; Belliveau, J.W.; Lewine, J.D.; Halgren, E. Dynamic statistical parametric mapping: Combining fMRI and MEG for high-resolution imaging of cortical activity. Neuron 2000, 26, 55-67. [CrossRef]

46. Pascual-Marqui, R.D. Discrete, 3D distributed, linear imaging methods of electric neuronal activity. Part 1: Exact, zero error localization. arXiv 2007, arXiv:0710.3341.

47. Jatoi, M.A.; Kamel, N.; Malik, A.S.; Faye, I. EEG based brain source localization comparison of sLORETA and eLORETA. Australas. Phys. Eng. Sci. Med. 2014, 37, 713-721. [CrossRef] [PubMed]

48. Gibbons, J.; Chakraborti, S. Nonparametric Statistical Inference; Springer: Berlin/Heidelberg, Germany, 2011.

49. Dauwels, J.; Vialatte, F.; Cichocki, A. Diagnosis of Alzheimer's disease from EEG signals: Where are we standing? Curr. Alzheimer Res. 2010, 7, 487-505. [CrossRef] [PubMed] 
50. Dattola, S.; Morabito, F.C.; Mammone, N.; La Foresta, F. Findings about LORETA Applied to High-Density EEG-A Review. Electronics 2020, 9, 660. [CrossRef]

51. Jatoi, M.A.; Kamel, N.; Malik, A.S.; Faye, I.; Begum, T. A survey of methods used for source localization using EEG signals. Biomed. Signal Process. Control 2014, 11, 42-52. [CrossRef]

(C) 2020 by the authors. Licensee MDPI, Basel, Switzerland. This article is an open access article distributed under the terms and conditions of the Creative Commons Attribution (CC BY) license (http:/ / creativecommons.org/licenses/by/4.0/). 